\title{
UK-Japan agreement to boost research collaboration
}

Tokyo. Britain's Prime Minister John Major and his Japanese counterpart, Morihiro Hosokawa, have agreed to recognize the political importance of the growing scientific links between their two countries by drawing up an umbrella agreement aimed at encouraging even greater collaboration between their researchers.

The agreement was reached during Major's visit to Japan two weeks ago, which was immediately followed by a separate visit by William Waldegrave, Britain's science minister. A draft agreement is being drawn up, and officials hope the final version will be ready within a few months.

At present, although a number of individual agreements exist between scientific institutions in the two countries, there is nothing comparable to that between Japan and several other leading industrial nations, in particular the United States.

An attempt to draw up such an agreement was blocked ten years ago when Japan rejected a British proposal that it should cover industrial research. The new agreement will be confined to collaboration between institutions in the public sector, although it is hoped that it will stimulate private sector cooperation. Even without an umbrella agreement, collaboration is flourishing, to judge from an exhibition of a handful of collaborative projects visited by Waldegrave at the British Embassy in Tokyo.

The star exhibit was a display of some of the results of observations of the Sun by the Japanese satellite Yohkoh which carries a spectrometer built by a UK consortium led by Mullard Space Science Laboratory of University College London. The project has produced X-ray video images of unprecedented clarity of sunspot activity during the present solar maximum.

Other exhibits were of a more industrial nature. For example, a consortium of five Japanese companies (Hitachi, Nissan,

\section{Software engineer acclaimed}

The National Academy of Engineering's Charles Stark Draper prize -- said, at $\$ 375,000$, to be the richest in the engineering world - has been awarded to 69 -yearold John Backus, who developed Fortran as the first-ever high-level computer language when working for IBM. Backus, who is now retired and living in San Francisco, is the third winner of the biennial award, which is intended to acknowledge "outstanding engineering achievement". Previous winners have been the inventors of the integrated circuit and the jet engine.
Yamaha, Bridgestone and MTT Instrumentation) is contributing $£ 3$ million over three years to a joint project between the University of Southampton and Tokyo Denki University to develop audio equipment applications of 'anti-sound' (the elimination of sound waves in a system by feeding in matching sound waves that are out of phase).

Waldegrave appears to have been particularly impressed by the joint development of information technology by the computer-maker ICL of the United Kingdom and Fujitsu, the Japanese company which is now a major shareholder in ICL. Nearly 20 British engineers from ICL have worked for two years at Fujitsu's laboratories in Kawasaki and Numazu, south of Tokyo, and a similar number of Fujitsu engineers have been assigned to ICL in Britain to develop products such as the intelligent pad', a software tool for the multiple display of data, video, and sound on computers.

Waldegrave said, in line with the British government's new policy of linking research to 'wealth creation', he is particularly keen to encourage collaborations that will result in the manufacture of new products in the United Kingdom. But much of the present collaborative research between Japan and Britain is of a more basic nature.

Minoru Oda, former president of the Institute of Physical and Chemical Research (RIKEN), who oversaw initial planning of the Yohkoh project when he was directorgeneral of the Institute of Space and Astronautical Science (ISAS) in the 1980s, admitted surprise at a British Embassy dinner attended by Waldegrave at the speed at which collaboration in science has developed over the past decade.

There are now more than 130 joint research projects between universities and national research institutes in Japan and Britain. Notable among them are the collaborations with ISAS, such as Yohkoh, a $\$ 5$-million programme on materials science at the University of Cambridge and Imperial College, London, funded by the Research Development Corporation of Japan, and a $£ 15$-million investment by RIKEN in a pulsed muon source at the Rutherford Appleton Laboratory in Britain.

Many Japanese electronics and pharmaceutical companies are also supporting basic research at Britain's universities and government laboratories. One example on display at the exhibition is the $£ 1$ million per year being invested by Teijin, a Japanese textile manufacturer, in research at the Medical Research Council's Collaborative Centre in Mill Hill, London, into ways of regenerating nerves in the central nervous system.

David Swinbanks

\section{Clinton moves to lift barriers on technology exports}

Washington. Computer users around the world can expect easier access to US-built machines following the Clinton administration's announcement last week that it is lifting export licensing requirements on powerful personal computers, Unix workstations and small supercomputers.

The shift is one of a set of decisions designed by the administration to demonstrate its determination to take a more proactive role in working with US industry. Other developments announced by President Bill Clinton and commerce secretary Ron Brown included a 65-point strategy to bolster US exports of manufactured goods, and a \$1-billion-a-year joint research initiative with the motor industry.

Current rules stating that computers the size of a standard 486-based $\mathrm{PC}$ require a licence for export will be lifted, to cover only machines 20 times as powerful. This threshold will be doubled again, once the necessary agreement is negotiated with the United States' partners in Cocom, the Parisbased trade control body.

Additionally, the lower memory limit used to define a supercomputer will be raised by a factor of ten, reflecting recent technological advances. Such machines are subjected to stringent rules by the US Department of Commerce, including security guards during transit to prevent theft.

The changes have been warmly welcomed by the US computer industry, which says that they will save a considerable amount of money, although industry officials decline to say how much. In practice their impact will be restricted: the larger companies are allowed to apply for export licenses to their most important Western markets en bloc, and restrictions on sales to the former Soviet Union and China are unaffected.

In a separate move, Clinton joined the presidents of Ford, Chrysler and General Motors on the White House lawn to announce a "partnership" to work on manufacturing technology, short-term development and long-term research, with the objective of developing vehicles capable of travelling 80 miles to the gallon. The programme will be managed by a team led by Mary Good, undersecretary of technology at the Department of Commerce, but will not initially involve new government expenditure.

A spokesman for the US Council for Automotive Research, which will coordinate participation by the automobile companies, says "They've agreed to do a programme but they don't have a roadmap for it yet." The government currently spends about $\$ 500$ million a year on automotive research, compared to the $\$ 11$ billion spent by the industry itself. 